\title{
Turgescence jugulaire
}

\section{Jugular venous distension}

\section{P. Ray}

Reçu le 21 novembre 2011 ; accepté le 7 janvier 2012

(C) SFMU et Springer-Verlag France 2012

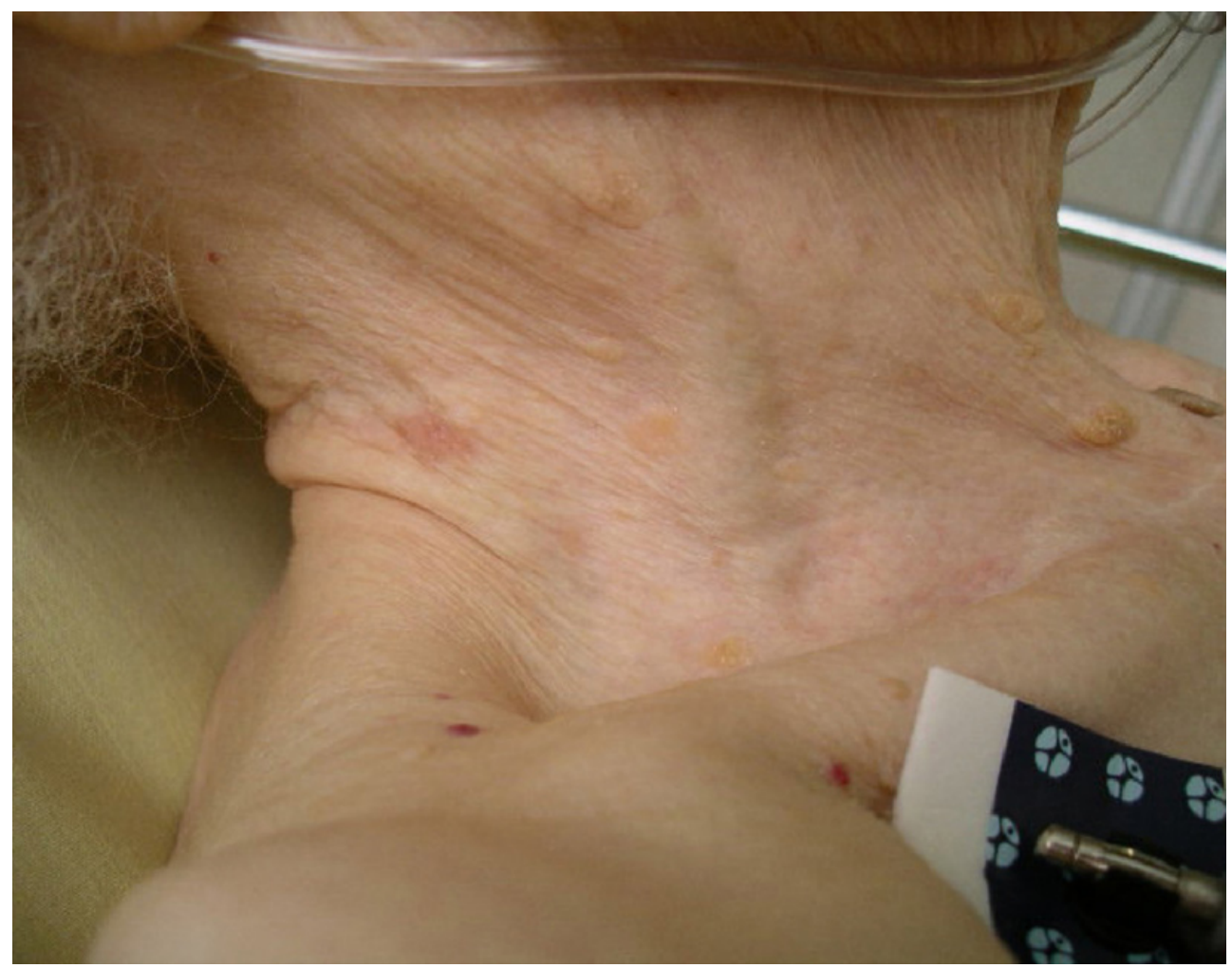

Fig. 1 Turgescence jugulaire

L'existence d'une turgescence jugulaire est fréquemment évaluée par les urgentistes pour le diagnostic d'insuffisance cardiaque aiguë. Malheureusement, ce test n'a une sensibilité que de $40 \%$ (même si sa spécificité est de $90 \%$ ) (Fig. 1) [1].

\section{Référence}

1. Wang CS, FitzGerald JM, Schulzer M, et al (2005) Does this dyspneic patient in the emergency department have congestive heart failure? JAMA, $294:$ 1944-56

P. Ray $(\bowtie)$

Service d'accueil des urgences,

Groupe hospitalier Tenon-Saint Antoine,

4, rue de la Chine, F-75020 Paris,

Université Pierre et Marie Curie-Paris 6, France

e-mail : patrick.ray@tnn.aphp.fr 